\title{
Development and Contribution of Multi-Parent Advanced Generation Inter-Cross Scheme in Rice Breeding: A review
}

\author{
Sisay Argaye* \\ Ethiopian Institutes of Agricultural Research, Holetta Agricultural Research Center, Ethiopia
}

*Corresponding Authors: Sisay Argaye, Ethiopian Institutes of Agricultural Research, Holetta Agricultural Research Center, Ethiopia

\begin{abstract}
Production of rice is negatively impacted by numerous biotic and abiotic stresses. Discovering the underlying genes affecting important traits like yield, quality, disease resistance, and climate adaptability is of par-amount importance to increase the agricultural productivity and to feed the world's growing population. Hence it is needed to mitigate production and productivity limiting biotic and abiotic stress through genetic improvement of the crops. Traditionally bi parental crosses are used to create genetic variability in rice breeding program. Accordingly, experimental design has re-focused on the levels of genetic recombination and diversity captured in mapping populations. The multi parent advanced generation inter-cross population is one of a new generation of emerging mapping resources within plant genetics. The main objective of this paper is to review the development and advantage of multi-parent advanced generation inter-cross scheme in rice breeding. Relative to bi-parental populations, multi-parent advanced generation inter-cross have an advantages' of: to create a greater genotypic diversity in the population, gives maximum number of informative crossovers, a higher level of recombination, and reduced linkage drag, important to develop recombinant inbreed lines that used to develop varieties which having good agronomic traits and lines derived from early generations can be used for QTL detection. In general, multi-parent advanced generation intercross scheme in rice populations provide a useful germplasm resource with diverse allelic combinations to be exploited by the rice community for further breeding program.
\end{abstract}

Keywords: Bi-parent, Generation, Inter-cross, Multi-parent, Rice

\section{INTRODUCTION}

Rice belongs to family Poaceae and genus Oryza and most probably originated in India or South Eastern Asia. Among the 40,000 varieties of rice cultivated worldwide, two rice species are Oryza sativa, grown worldwide, and Oryza glaberrima, grown in parts of West Africa. The Asian rice is grown all over the world while African rice has originated and been cultivated in West Africa for about more than 3500 years (Martin et al., 2006). Oryza sativa has two major subspecies: the Indica, long-grain rice and the Japonica, round-grain rice. Indica and japonica rice represent 80 and $20 \%$, respectively, of the world rice production. It is the world's second most important cereal crop next to wheat.

The cultivated rice plant is an annual grass and grows to about 1.2 meter in height. The leaves are long and flattened and are borne on hollow stems. The fibrous root system is often broad and spreading. The panicle, or inflorescence (flower cluster), is made up of spikelet bearing flowers that produce the fruit, or grain (McDonald, 1979). Varieties differ greatly in the length, shape, and weight of the panicle and the overall productivity of a given plant. It has a semi aquatic lifestyle, requiring water particularly during the reproductive growth phase.

The global production of rice is about 730 million tones and the cultivated area is estimated as 163 million hectares (FAOSTAT, 2013). Rice is main source of complex carbohydrates and makes up as much as two thirds of calorie intake for more than three billion people in Asia and one-third of calorie intake of nearly 1.5 billion people in Africa and Latin America (Khan et al. 2015). Throughout history, rice has been one of the most important food crops for humans. It is deeply embedded in the cultural and economic heritage of their societies. About four-fifths of the world's rice is produced on small-scale by farmers and is consumed locally. Rice has the ability to provide fast and instant energy. 
Brown rice and red rice are great sources of vitamins B, calcium, zinc and iron, manganese, selenium, magnesium and other important nutrients.

Production of rice is negatively impacted by numerous biotic and abiotic stresses. Among the biotic factors, rice is susceptible to a wide range of diseases, the most important of which are brown leaf spot, blast, sheath rot, sheath blight and bacterial leaf blight. Insects not only cause direct losses to the agricultural produce but also act as vectors for various plant pathogens that causes disease. The most known pests of rice are brown plant hopper, green leafhopper and white backed plant hopper are known to cause severe damage. The common environmental stresses in rice include drought, high temperature, salinity, alkalinity and submergence.

To satisfy the growing demand of rice in the future, scientists discovering genes affecting important traits like yield, quality, disease resistance, and climate adaptability is of par-amount importance to increase the agricultural productivity needed to feed the world's growing population. Plant breeding deals with favorably changing the genetic constitution of crop plants to the interest of man for desirable agronomic and economic traits. The presence of genetic variability is a prerequisite for crop improvement. Furthermore, Upadhyaya et al. (2011) reported the importance of utilizing this diversity in breeding programs in order to develop varieties with high yielder and resistance to stress.

Therefore, creation of genetic variation is the first step. In the absence of desired variability from the existing materials, hybridization is the best method to create variability. The extent of diversity present between genotypes determines the extent of improvement gained through selection and hybridization. The more divergent the two genotypes are the more will be the probability of improving through selection and hybridization. Hybridization signifies the extent of genetic diversity and that is of practical use in plant breeding (Sultana et al., 2006).

Based on the taxonomic relationships between the two parents, hybridization may be grouped as intraspecific and interspecific. When the parents involved in the crossing program belong to the same species, it is referred to as intraspecific or intervarietal hybridization. Contrarily, when the parents involved in the crossing program belong to the different species of a genus, it is referred to as interspecific or distant hybridization.

Intraspecific or intervarietal hybridization could be reclassified as simple or complex based on the number of parents involved. Crosses can be single, when only two parents are involved, and multiple, when more than two parents are involved. If three parents, namely A, B and C are involved, it is referred to as three-way cross e.g. [(A x B $) \times$ C]. Similarly, if four parents are involved, then it is referred to as a double cross [e.g. [(A x B $) \times(\mathrm{D} \times \mathrm{D})$ ], and so on. Traditionally bi parental crosses are used to create genetic variability in rice breeding program. Accordingly, experimental design has refocused on the levels of genetic recombination and diversity captured in mapping populations.

The main objective of this paper is to review the development and advantage of multi-parent advanced generation inter-cross scheme in rice breeding.

Multi parent advanced generation inter-cross population is one of a new generation of emerging mapping resources within plant genetics. In crops, the approach was first advocated in 2007 (Mackay and Powell 2007; Cavanagh et al., 2008). MAGIC populations are multi-founder equivalents of the advanced intercross introduced by Darvasi and Soller (1995) and are very similar to the heterogeneous stock and collaborative cross populations used in mouse genetics (Mott et al. 2000; Threadgill and Churchill, 2012). They are created by several generations of intercrossing among multiple founder lines. Multiple founders contribute more allelic diversity than that captured in typical bi-parental mapping populations, whereas the multiple cycles of intercrossing give greater opportunities for recombination and, hence, greater precision in QTL location.

\section{Historical DeVELOPMENT OF MUlti-PARENT ADVANCED GENERATION INTER-CROSS}

The first multi parental intermated population was the collaborative cross Consortium (2004) in mice, but the design has since had wide uptake across a variety of species. The collaborative cross combined the genomes of eight inbred strains together through multiple intercrosses, and then created inbred lines through sibling mating. A similar design was used to create the drosophila synthetic population resource (King et al., 2012). In plants, there has been more variety in the features of different populations, due to many differences between organisms including genome size and complexity, history of the species, and resources and technologies available. Multi-parent advanced generation inter-cross populations are now available in a range of plant and crop species, including Arabidopsis 
Development and Contribution of Multi-Parent Advanced Generation Inter-Cross Scheme in Rice Breeding: A review

(Kover et al., 2009), rice (Bandillo et al., 2013), in wheat (Huang et al., 2012) and in chickpea (Gaur et al., 2012).

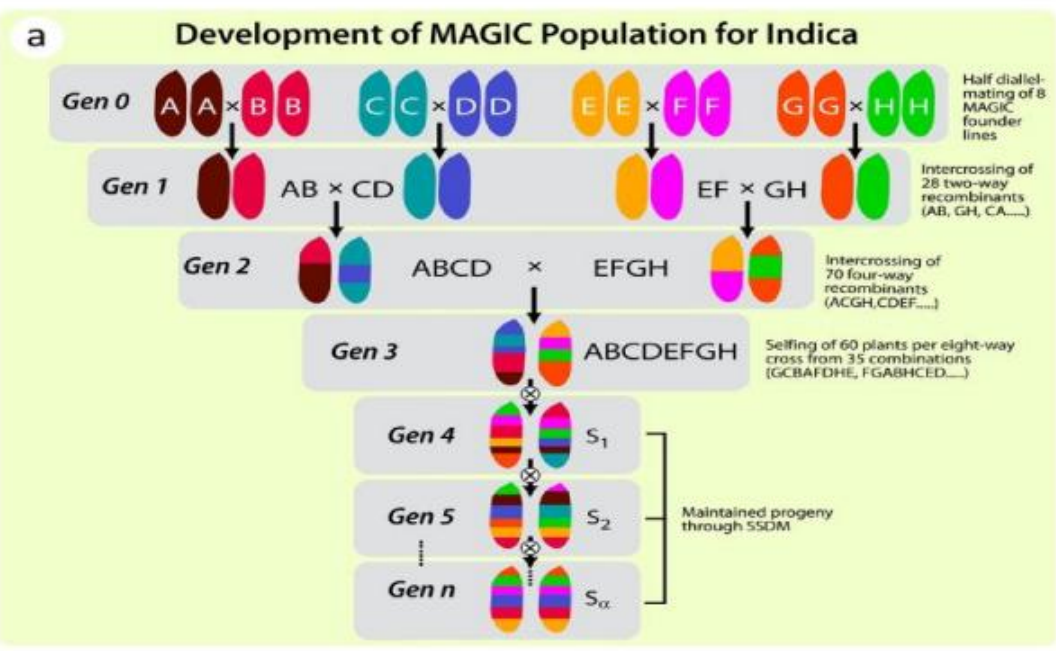

b Development of MAGIC-Plus and MAGIC Global Populations

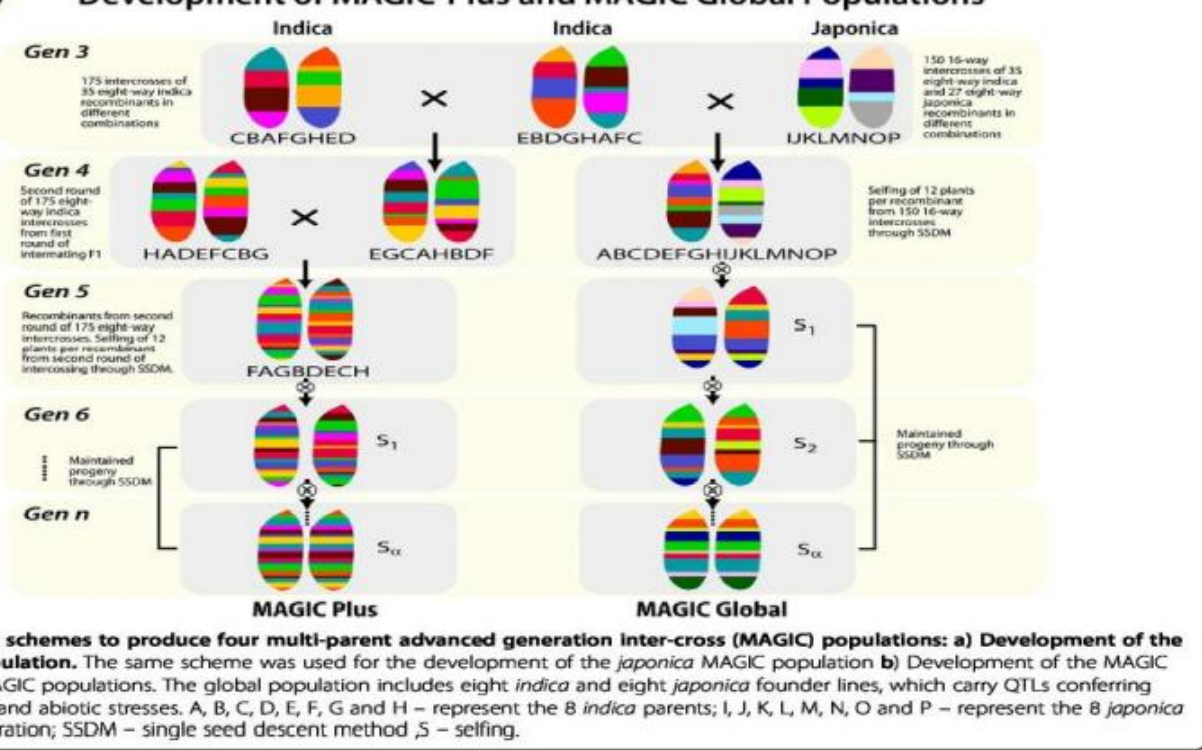

Figure1. Crossing scheme for developing multi parent advanced generation inter-cross population in rice breeding.

Source: (Bandillo et al., 2013)

\section{Procedure For Multi-Parent AdVAnCEd Generation InTER-Cross}

\section{Founder selection}

Prior to making hybridization or crossing, the breeder must know what is lacking in the crop he is working with and he must clearly define the type of variety he wants to produce and the important character he wishes to improve. Then he has to search for suitable parents, which will contribute these characters, and use them in an appropriate hybridization program. Hybridization programs so far focused mostly on high-yield, resistance to diseases, resistance/ tolerance to insect, weed free, resistance/tolerance to environmental stress likes: drought, high temperature, salinity, alkalinity and submergence. Selection of appropriate parental materials is the most crucial job of a plant breeder for effective hybridization.

The success of hybridization program largely depends on the extent of genetic variation between materials intended for crossing. Choice of parents based on genetic divergence offer substantial variability that reflects in segregating generations. Thus, selection of desirable recombinants becomes 
easy. Hybridization of parents with similar genetic background is not likely to produce higher heterosis, desirable genetic recombination and segregation in progenies. One has to be sure about the existence of genes controlling the desired trait in one of the parents. In cases all the desired attributes are not present in the two parents; more than two parents can be chosen for crossing in three-way or four-way crosses. Traits of interest depend on the specific objective of the breeder.

\section{Mixing}

In the first stage of population development, multiple parents are intercrossed to form a broad genetic base (Figure 1b). This was inspired by the heterogeneous stock, proposed by (McClearn et al., 1970) and taken up by Demarest et al. (2001), which goes on to create an out bred population derived from multiple parents. In this stage, the inbred founders are paired off and inter-mated in a prescribed order for each line, known as a funnel. If each recombinant inbred line is the product of a 2 n-way cross, then the mixing stage will require $\mathrm{n}$ generations. The result of this stage is a set of lines whose genomes comprised contributions from each of the founders. Broman (2005) showed that the composition of these contributions depends on the funnel structure; hence, the design and selection of funnels used in the cross will impact on the eventual genetic makeup of the population.

Greater variety in the types of funnels generated will ensure greater robustness to accounting for factors such as maternal effects, population structure, and segregation distortion; however, it will require greater investment in terms of cost and time. Advanced intercrossing in the second stage (Figure 1), the mixed lines from different funnels are randomly and sequentially intercrossed as in the advanced intercross proposed by Darvasi and Soller (1995). The main goal of this intercrossing is to increase the number of recombination in the population. Yamamoto et al. (2014) performed a simulation study to consider the effect of different numbers of generations of intercrossing on genome structure. They concluded that at least six cycles of inter-crossing were required for large improvements in QTL mapping power. Lines undergoing differing generations of advanced intercrossing may be combined together in the analysis.

\section{Inbreeding}

The parents chosen for hybridization must be pure lines as much as possible. A pure line that is not suitable for release as a variety may serve as a parent in the development of new varieties. Hybridization programs are largely dependent on pure-lines; some of these pure-lines may not be suitable for use as commercial varieties. Rice is a self-pollinated crop and pure-line development is possible easily possible through selfing without problem of inbreeding depression.

The individuals resulting from the advanced intercrossing stage are progressed to create homozygous individuals (Figure 1). In plants can be created via single seed descent (Goulden, 1939; Brim, 1966; Bailey, 1971) or doubled haploid production (Blakeslee et al., 1922; Maluszynski et al., 2003; Forster et al., 2007). While doubled haploid production is often faster, the multiple generations of selfing will introduce additional recombination, albeit less than during the mixing and advanced inter-crossing stages

\section{The Advantages of Multi Parent advance Generation Intercross Scheme In RICE BREEDING}

Creates new genetic diversities in the population

The use of landraces for breeding is often hampered by linkage drag. To make use of the diversity, an efficient mating design is needed to break the undesirable linkages and to convert landraces to breeding-ready genetic resources. Some crops have narrow genetic diversity for key traits within their domesticated cultivated bases. Bringing in new alleles is therefore a must to make significant progress in breeding. This can be achieved by developing 'wild $\times$ domesticated' synthetics, creating new diversity by introgressing favorable alleles through polyploidy, for breeding from wild relatives into cultivars. New genetic diversity is created through recombination, that is, through crossing contrasting materials to create novel haplotypes. Generally multi-parent advance generation intercross design can help convert useful diversity into breeding ready genetic resources.

\section{Gives maximum number of informative crossovers}

To compare utility of different types of populations for mapping, Broman (2005) calculated the number of cross-over's that accumulate in offspring population (i.e. number of informative crossovers) in different mapping populations. For backcross population, or a double haploid 
population, the expected number of informative crossover per Morgan distance for a single offspring $(\gamma)$ is 1 . In case of two-way and four-way $\gamma$ is 2 and 3, respectively. For MAGIC population, $\gamma=6$ (Kover et al., 2009). Thus, MAGIC gives maximum number of informative crossovers among different mapping populations.

\section{Quantitative trait loci mapping}

Most standard quantitative trait locus mapping procedures apply to populations derived from the cross of two parents. QTL detected from such bi-parental populations are rarely relevant to breeding programs due to the narrow genetic basis; only two alleles are involved per locus or there is the reduction of genetic heterogeneity (compared with the total genetic variations available for a species. Only two allelic variations are analyzed in a bi parental population, which means that the useful and naturally occurring alleles from other genotypes may be missed (Guo and Ye, 2014). Such populations also have other limitations mainly, they principally rely on the recombination events taking place in F1generation and not enough time is available to shuffle the genome in small fragments, populations are not fixable due to their inherent heterozygous genetic constitution and Second limitation of bi parental cross-derived mapping populations that, it allows mapping of only the allelic pairs present in the two parents. Thus, the whole genetic variation cannot be exploited in such studies. These MAGIC populations provide a useful germplasm resource with diverse allelic combinations to be exploited by the rice community. This increases the potential of capturing novel QTLs with small genotypic variance and QTL combinations to enhance the improvement of complex traits.

\section{Blast disease}

Blast disease, caused by Magnaporthe oryzae, is one of the most important fungal diseases of rice, causing significant yield losses in many rice producing areas. To date, a number of Pi genes contributing to the resistance of blast disease have been identified and cloned with the most important ones being located on chromosomes 1, 2, 6, 8, 11 and 12 (Ballini et al. 2008). Similarly, Bandillo et al. (2013) detects q2p5, q3fp1, pi28 and pi42 genes on chromosomes 2, 3, 9 from MAGIC population on rice.

\section{Bacterial blight}

Bacterial blight is one of the most serious and widespread diseases in rice production and it caused by Xanthomonas oryzae. It reduces the yield of rice drastically by partial grain filling because of constraint to the photosynthetic area (Pradhan et al., 2015). There are no effective chemical agents against the bacterial blight pathogen. The only way to protect the crop from bacterial blight is the use of resistant varieties of rice (Khush et al., 1989). So far, more than 30 bacterial blight resistance genes have been identified and some of them have been incorporated in to modern high yielding rice varieties (Dokku et al., 2013; Suh et al., 2013; Kumar et al., 2014; Pradhan et al., 2015). Likewise Bandillo et al. (2013) from MAGIC population on rice, detects $x 4$ resistance genes for strain (PXO61), (PXO341) and (PXO99) on chromosomes 11 and x5 resistance gene for strain (PXO86) on chromosomes 5.

\section{Salt tolerance}

Salinity is a wide-spread abiotic stress especially in the rainfed lowlands near coastal regions. Salinity may constrain rice production due to sensitivity of rice at seed-ling and reproductive stages (Singh and Flowers, 2010). A number of genes such as qSKC-1 and Saltol contributing to tolerance to salt tolerance have been identified by Alam et al. (2011) and Thomson et al.

(2010). Similarly Bandillo et al. (2013) from MAGIC population, detects saltol genes on chromosome one.

\section{Submergence tolerance}

Among the abiotic stresses, submergence is one of the vital issues in the flash flood prone rice cultivating areas (Iftekharuddaula et al., 2015). Submergence tolerance is an important trait for rice in rain-fed lowland conditions. This trait is largely controlled by a major gene designated as Sub1.The Subl gene positioned on rice chromosome 9 was well-known as a foremost gene conferring submergence tolerance in tolerant rice cultivar FR13A and its derived progenies (Xu and 
Mackill, 1996; Xu et al., 2004; Toojinda et al., 2003; Manivong et al., 2014). Similarly, Bandillo et al. (2013) from MAGIC population, detects Sub1 genes on chromosome 9.

\section{Grain quality}

The rice qualities include the appearance, milling quality, nutritional quality, and eating and cooking quality appearance have received more attention than other qualities in rice from consumers $(\mathrm{He} \mathrm{P}$, 1999). Grain and cooking quality are essential characteristics of rice varieties and hence several key quality traits were evaluated, including amylose content, grain shape and gelatinization temperature.

\section{Amylose content}

Amylose content is a key determinant of cooking quality and consumer preferences. waxy gene for amylose content were detected on chromosome 6 at $1.7 \mathrm{Mb}$ by Zheng et al. (2008). Similarly Bandillo et al. (2013) detect waxy genes on chromosome 6 [[

\section{Grain length}

GS3 major gene for grain length was detected on chromosome number 3 by Fan et al. (2006). Similarly Bandillo et al. (2013) detects GS3 genes on chromosome 3.

\section{Grain weigh}

Grain width, genes for grain weight was identified on chromosome 7 by Redoña and Mackill (1998) and qGW-5 genes for grain weight which was identified on chromosome 5 by Weng et al. (2008). Additionally GW8 also identified for grain width and yield potential on chromosome 8 by Wanget al. (2012). Similarly Bandillo et al. (2013) they detects GB, qGW-5 and GW8 genes for grain weight on chromosome 7, 5 and 7 respectively. Detection of those genes for grain weight from MAGIC population was confirmed with the result obtained by Redoña and Mackill (1998); Weng et al. (2012).

\section{Gelatinization temperature}

Gelatinization temperature is the temperature at which starch granules start to lose crystallinity and birefringence by irreversible expansion that alters the starch surface from polarized to a soluble state (Gao Z et al., 2003). Starch synthase gene (SSIIa) that coincided for starch gelatinization temperature that is used to assess cooking time or quality which was identified on chromosome 6 by Waters et al. (2006). Similarly Bandillo et al. (2013) detects SSIIa gene on chromosome 6. Detection of this synthase gene (SSIIa) for gelatinization temperature from MAGIC population was confirmed with the result obtained by Waters et al. (2006).

\section{CONCLUSION}

Multi parent advanced generation inter-cross approach can be adopted to build pre-breeding populations accessible to breeding programs. Although more time and efforts may be required to develop the populations, The potential benefits are large relative to bi-parental populations, it will have greater genotypic diversity, gives maximum number of informative crossovers, a higher level of recombination, and reduced linkage drag important to develop recombinant inbreed lines that used to develop varieties which having good agronomic traits.

Lines derived from early generations can be used for QTL detection; this increases the potential of capturing novel QTLs with small genotypic variance and QTL combinations to enhance the improvement of rice varieties resistance to biotic and a biotic stress. These Multi parent advanced generation inter-cross population provide a useful germplasm resource with diverse allelic combinations to be exploited by the rice community for further breeding program.

\section{REFERENCES}

[1] Alam, R., Sazzadur Rahman, M., Seraj, Z.I., Thomson, M.J., Ismail, A.M., Tumimbang- Raiz, E. and Gregorio, G.B., 2011. Investigation of seedling- stage salinity tolerance QTLs using backcross lines derived from Oryza sativa L. Pokkali. Plant Breeding, 130(4), pp.430-437.

[2] Bailey, D.W., 1971. Recombinant-inbred strains an aid to finding identity, linkage, and function of histocompatibility and other genes. Transplantation, 11(3), pp.325-327. 
[3] Ballini, E., Morel, J.B., Droc, G., Price, A., Courtois, B., Notteghem, J.L. and Tharreau, D., 2008. A genome-wide meta-analysis of rice blast resistance genes and quantitative trait loci provides new insights into partial and complete resistance. Molecular Plant-Microbe Interactions, 21(7), pp.859-868.

[4] Bandillo, N., Raghavan, C., Muyco, P.A., Sevilla, M.A.L., Lobina, I.T., Dilla-Ermita, C.J., Tung, C.W., McCouch, S., Thomson, M., Mauleon, R. and Singh, R.K., 2013. Multi-parent advanced generation intercross (MAGIC) populations in rice: progress and potential for genetics research and breeding. Rice, 6(1), pp.1-15.

[5] Blakeslee, A.F., Belling, J., Farnham, M.E. and Bergner, A.D., 1922.A haploid mutant in the jimson weed," Datura stramonium". Science, 55(1433), pp.646-647.

[6] Brim, C.A., 1966. A modified pedigree method of selection in soybeans 1.Crop science, 6(2), pp.220-220.

[7] Broman, K.W., 2005. The genomes of recombinant inbred lines. Genetics, 169(2), pp.1133-1146.

[8] Cavanagh, C., Morell, M., Mackay, I. and Powell, W., 2008. From mutations to MAGIC: resources for gene discovery, validation and delivery in crop plants. Current opinion in plant biology, 11(2), pp.215221.

[9] Chakrabarti, N.K., 2001. Epidemiology and disease management of brown spot of rice in India.In Major Fungal Diseases of Rice (pp. 293-306).Springer, Dordrecht.

[10] Churchill, G.A., Airey, D.C., Allayee, H., Angel, J.M., Attie, A.D., Beatty, J., Beavis, W.D., Belknap, J.K., Bennett, B., Berrettini, W. and Bleich, A., 2004. The Collaborative Cross, a community resource for the genetic analysis of complex traits. Nature genetics, 36(11), p.1133.

[11] Darvasi, A. and Soller, M., 1995.Advanced intercross lines, an experimental population for fine genetic mapping.Genetics, 141(3), pp.1199-1207.

[12] Demarest, K., Koyner, J., McCaughran, J., Cipp, L. and Hitzemann, R., 2001. Further characterization and high-resolution mapping of quantitative trait loci for ethanol-induced locomotor activity.Behavior genetics, 31(1), pp.79-91.

[13] Dokku, P., Das, K.M. and Rao, G.J.N., 2013. Pyramiding of four resistance genes of bacterial blight in Tapaswini, an elite rice cultivar, through marker-assisted selection.Euphytica, 192(1), pp.87-96.

[14] Fan, C., Xing, Y., Mao, H., Lu, T., Han, B., Xu, C., Li, X. and Zhang, Q., 2006. GS3, a major QTL for grain length and weight and minor QTL for grain width and thickness in rice, encodes a putative transmembrane protein. Theoretical and applied genetics, 112(6), pp.1164-1171.

[15] FAOSTAT ( 2013). Food and Agriculture Organization of the United Nations Statistical, Rome, Italy.

[16] Forster, B.P., Heberle-Bors, E., Kasha, K.J. and Touraev, A., 2007.The resurgence of haploids in higher plants.Trends in plant science, 12(8), pp.368-375.

[17] Gao, Z., Zeng, D., Cui, X., Zhou, Y., Yan, M., Huang, D., Li, J. and Qian, Q., 2003. Map-based cloning of the ALK gene, which controls the gelatinization temperature of rice.Science in China Series C: Life Sciences, 46(6), pp.661-668.

[18] Gaur, P.M., Jukanti, A.K. and Varshney, R.K., 2012.Impact of genomic technologies on chickpea breeding strategies.Agronomy, 2(3), pp.199-221.

[19] Goulden, C.H., 1939. Problems in plant selection.Proc. Seventh Genet.Cong. Cambridge University Press, pp.132-133.

[20] GUO, L.B. and YE, G.Y., 2014.Use of major quantitative trait loci to improve grain yield of rice.Rice science, 21(2), pp.65-82.

[21] He, P., Li, S.G., Qian, Q., Ma, Y.Q., Li, J.Z., Wang, W.M., Chen, Y. and Zhu, L.H., 1999.Genetic analysis of rice grain quality.Theoretical and Applied Genetics, 98(3-4), pp.502-508.

[22] Huang, B.E., George, A.W., Forrest, K.L., Kilian, A., Hayden, M.J., Morell, M.K. and Cavanagh, C.R., 2012. A multiparent advanced generation inter- cross population for genetic analysis in wheat. Plant biotechnology journal, 10(7), pp.826-839.

[23] Huang, B.E., Verbyla, K.L., Verbyla, A.P., Raghavan, C., Singh, V.K., Gaur, P., Leung, H., Varshney, R.K. and Cavanagh, C.R., 2015. MAGIC populations in crops: current status and future prospects. Theoretical and Applied Genetics, 128(6), pp.999-1017.

[24] Iftekharuddaula, K.M., Ahmed, H.U., Ghosal, S., Moni, Z.R., Amin, A. and Ali, M.S., 2015. Development of new submergence tolerant rice variety for Bangladesh using marker-assisted backcrossing.Rice Science, 22(1), pp.16-26.

[25] Khush, G.S., Mackill, D.J. and Sidhu, G.S., 1989. Breeding rice for resistance to bacterial blight.Bacterial blight of rice, pp.207-217. 
[26] King, E.G., Merkes, C.M., McNeil, C.L., Hoofer, S.R., Sen, S., Broman, K.W., Long, A.D. and Macdonald, S.J., 2012. Genetic dissection of a model complex trait using the Drosophila Synthetic Population Resource.Genome research, 22(8), pp.1558-1566.

[27] Kover, P.X., Valdar, W., Trakalo, J., Scarcelli, N., Ehrenreich, I.M., Purugganan, M.D., Durrant, C. and Mott, R., 2009. A multiparent advanced generation inter-cross to fine-map quantitative traits in Arabidopsis thaliana. PLoS Genet, 5(7), p.e1000551.

[28] Kumar, A., Dixit, S., Ram, T., Yadaw, R.B., Mishra, K.K. and Mandal, N.P., 2014. Breeding high-yielding drought-tolerant rice: genetic variations and conventional and molecular approaches. Journal of experimental botany, 65(21), pp.6265-6278.

[29] Mackay, I. and Powell, W., 2007.Methods for linkage disequilibrium mapping in crops.Trends in plant science, 12(2), pp.57-63.

[30] Mackay, I.J., Bansept-Basler, P., Barber, T., Bentley, A.R., Cockram, J., Gosman, N., Greenland, A.J., Horsnell, R., Howells, R., O'Sullivan, D.M. and Rose, G.A., 2014. An eight-parent multiparent advanced generation inter-cross population for winter-sown wheat: creation, properties, and validation. G3: Genes, Genomes, Genetics, 4(9), pp.1603-1610.

[31] Maluszynski, M., Kasha, K., Forster, B.P. and Szarejko, I. eds., 2003.Doubled haploid production in crop plants: a manual.Springer Science \& Business Media.

[32] Manivong, P., Korinsak, S., Korinsak, S., Siangliw, J.L., Vanavichit, A. and Toojinda, T., 2014.Markerassisted selection to improve submergence tolerance, blast resistance and strong fragrance in glutinous rice.Genomics and Genetics, 7(2), pp.110-122.

[33] Martin, J.H., Stamp, D.L. and Waldren, R.P., 2006. Principles of field crop production 4th Ed.

[34] McDonald, D.J. (1979). Rice.Chapter 3. In: Australian field crops vol 2: Tropical cereals, oilseeds, grain legumes and other crops. Angus and Robertson, London. pp 70 -94.

[35] Mott, R., Talbot, C.J., Turri, M.G., Collins, A.C. and Flint, J., 2000. A method for fine mapping quantitative trait loci in outbred animal stocks.Proceedings of the National Academy of Sciences, 97(23), pp.12649-12654.

[36] Poehlman, J. M. and Sleper, D.A., 1995. Breeding Field Crops, (4th ed).Iowa State University Press. Ames, Iowa.

[37] Pradhan, S.K., Nayak, D.K., Mohanty, S., Behera, L., Barik, S.R., Pandit, E., Lenka, S. and Anandan, A., 2015. Pyramiding of three bacterial blight resistance genes for broad-spectrum resistance in deepwater rice variety, Jalmagna.Rice, 8(1), pp.1-14.

[38] Redona, E.D. and Mackill, D.J., 1998. Quantitative trait locus analysis for rice panicle and grain characteristics.Theoretical and Applied Genetics, 96(6), pp.957-963.

[39] Singh, R.K. and Flowers, T.J., 2010. 36 The Physiology and Molecular Biology of the Effects of Salinity on Rice.

[40] Suh, J.P., Jeung, J.U., Noh, T.H., Cho, Y.C., Park, S.H., Park, H.S., Shin, M.S., Kim, C.K. and Jena, K.K., 2013. Development of breeding lines with three pyramided resistance genes that confer broad-spectrum bacterial blight resistance and their molecular analysis in rice.Rice, 6(1), pp.1-11.

[41] Sultana, T., Ghafoor, A. and Ashraf, M., 2006. Geographic patterns of diversity of cultivated lentil germplasm collected from Pakistan, as assessed by seed protein assays. ActaBiologicaCracoviensia, Series Botanica, Poland, 48(1): 77-84.

[42] Thomson, M.J., de Ocampo, M., Egdane, J., Rahman, M.A., Sajise, A.G., Adorada, D.L., TumimbangRaiz, E., Blumwald, E., Seraj, Z.I., Singh, R.K. and Gregorio, G.B., 2010.Characterizing the Saltol quantitative trait locus for salinity tolerance in rice.Rice, 3(2-3), pp.148-160.

[43] Threadgill, D.W. and Churchill, G.A., 2012. Ten years of the collaborative cross. G3: Genes| Genomes| Genetics, 2(2), pp.153-156.

[44] Toojinda, T., Siangliw, M., Tragoonrung, S. and Vanavichit, A., 2003. Molecular genetics of submergence tolerance in rice: QTL analysis of key traits. Annals of Botany, 91(2), pp.243-253.

[45] Upadhyaya HD, Dronavalli N, Gowda CLL, Singh, S., 2011. Identification and evaluation of chickpea germplasm for tolerance to heat stress. Crop Science, 51(5):2079-2094

[46] Wang, S., Wu, K., Yuan, Q., Liu, X., Liu, Z., Lin, X., Zeng, R., Zhu, H., Dong, G., Qian, Q. and Zhang, G., 2012.Control of grain size, shape and quality by OsSPL16 in rice.Nature genetics, 44(8), p.950.

[47] Wilson, J.R. and Meredith, W., 1970.The use of isogenic and heterogenic mouse stocks in behavioral research. P. 3-22. In g. Lindzey\& d. D. Thiessen (ed.), Contrib.To behavior-genetic.

[48] Xu K., Deb R., Mackill D. J., 2004. A microsatellite marker and a co dominant PCR-based marker for marker-assisted selection of submergence tolerance in rice. Crop Sci. 44, 248-253. 
[49] Xu K., Mackill D. J., 1996. A major locus for submergence tolerance mapped on rice chromosome 9.Mol. Breed. 2, 219-224.

[50] Xu K., Xu X., Ronald P. C., Mackill D. J., 2000. A high-resolution linkage map in the vicinity of the rice submergence tolerance locus Sub1. Mol. Gen. Genet. 263, 681-689.

[51] Yamamoto E, Iwata H, Tanabata T, Mizobuchi R, Yonemaru J., 2014. Effect of advanced intercrossing on genome structure and on the power to detect linked quantitative trait loci in a multi-parent population: a simulation study in rice. BMC Genet 15:50

[52] Zheng X, Wu JG, Lou XY., 2008. The QTL analysis on maternal and endosperm genome and their environmental interactions for characters of cooking quality in rice (OryzasativaL.). Theor Appl Genet 116:335-34

Citation: Sisay Argaye, (2021). "Development and Contribution of Multi-Parent Advanced Generation Inter-Cross Scheme in Rice Breeding: A review ", International Journal of Research Studies in Agricultural Sciences (IJRSAS), 7(5), pp. 18-26 DOI: http://dx.doi.org/10.20431/2454-6224.0705003

Copyright: (C) 2021 Authors. This is an open-access article distributed under the terms of the Creative Commons Attribution License, which permits unrestricted use, distribution, and reproduction in any medium, provided the original author and source are credited. 